\title{
Developing Context-Based Science Curriculum: Humanizing Science Curriculum
}

\author{
Mohammed Yousef Mai \\ Faculty of Education, Universiti Pendidikan Sultan Idris, 35900 Tanjong Malim, Perak Darul Ridzuan \\ dr.mohd.mai@gmail.com
}

\section{Doi:10.5901/ajis.2015.v4n1s1p171}

\section{Abstract}

For many researchers, a humanistic approach is the most pervasive alternative to the traditional science curriculum (Aikenhead, 2007). Numerous reports and commissions address the need to reform science education in elementary and high schools. In the USA, for example, many reports call for changes in science education that ought to provide functional and useful learning for all students (Yager, 2002). In recent years, there is a new form of education being adopted worldwide. According to this new trend, the progress of learning science and the development and applications of new technology is naturally a social process. The purpose of this research is to describe the process of developing context-based science curriculum. The process of curriculum development starts with the "situation analysis" stage, this is done through documentary analysis and the review of the previous studies on science education. As a result, the proposed developed context-based physics curriculum caters for relevant objectives, content, learning activities, and evaluation methods.

Keywords: Curriculum development, models of curriculum development, context based curriculum, science education.

\section{Introduction}

The curriculum reform is sharply associated with the educational characteristics of science education and the humanities (Donnelly, 2004). According to Aikenhead (2007): "a humanistic approach to school science aims to prepare future citizens to critically and rationally assess science and technology. This goal views science as a human endeavor embedded within a social milieu of society and carried out by various social communities of scientists".

Recent researches decleared that current reform in science education demands more emphasis on the nature of science and scientific inquiry, as well as development of broad conceptual frameworks for scientific literacy that require a commitment to the social, moral and ethical dimensions of science education (Zeidler, Sadler, Simmons, \& Howes, 2005).

Worldwide, science education should develop the students' understanding of their enviernoment and its effects on human living. On the other hand, science education should explain to students how human living affects the environment. National Science Teachers Association (NSTA) outlines a contemporary set of curriculum goal clusters for science, the goal clusters includeYager (1993):

1. Personal Needs: Science education should:

- $\quad$ prepare individuals to utilize science for improving their lives.

- $\quad$ prepare individuals for coping with an increasingly technological world.

2. Societal Issues: Science education should develop informed citizens to deal responsibly with societal issues related to science.

3. Academic Preparation: Science education should help students to acquire the academic knowledge appropriate for their needs.

4. Career Education/Awareness: Science education should help students to be aware of the nature of science and technology-related careers open to students of varying aptitudes and interests.

Recently, professionals in science education recognize the importance of preparing scientific literate students to involve in informed decision-making. Such students will be able to analyze, synthesize, and evaluate information; and to deal sensibly with moral reasoning and ethical issues (Zeidler et al., 2005). Consequently, science curriculum must ought to enhance the personal development of students and contribute to their lives as citizens.

In reality, students struggle to figure out their everyday experiences, and they do not feel that science curriculum relates to their daily lives because they do not apply scientific knowledge outside the classroom. Aikenhead (2005) observes that learning formal science content is meaningless and just not achievable for the majority of science students in the traditional school science (Aikenhead, 2005). According to Eijkelhof and Lijnse (1988), it would be important and 
necessary to develop new science curricula. This could be accomplished by changing some of the traditional practices, focusing more on helping students to think rather than memorize facts, and to attempt to change the curriculum as well. The developed "curriculum" should be holistic instead of containing abstract subjects to be covered. In fact, we need to make prominent changes in science curriculum and instruction to get a science curriculum that is for all students.

NSTA in US in its report "Science Education for Middle and Junior High Students" recommends the following: "The primary function of science education at the middle and junior high level is to provide students with the opportunity to explore science in their lives, and to become comfortable and personally involved in it" (Brunhorst \& Padilla, 1986).

Blosser \& Helgeson declare that the main purpose of a science curriculum is to create scientific literate citizens. Such citizen will be able to participate intelligently and to make decisions regarding the interrelationship between science, technology and society and how each one of them can change the others. Such science curriculum is human and society focused, problem centered, and responsive to local issues (Blosser \& Helgeson, 1990).

Professional science educators have framed the science education problem in different terms. Yager (1991) sums up the crisis in science education in two related problems: the first is general while the second is specific. The general problem refers to the greatest failure of science education "as not bringing about mass scientific /technological literacy among our citizenry". According to Yager, science students remember little of what they have been taught in their science classroom. On the other hand, they ultimately express less interest in studying more science after taking a formal course than before (Cited in: (Wraga \& Hlebowitsh, 1991)).

Pondering over many studies, Yager (1993) concludes that the most critical problems with traditional science teaching are:

1. Students cannot use science (either concepts or processes) that they learn in their daily life. They have a large number of misconceptions.

2. Moreover, $90 \%$ of students graduated from high school do not have scientific literacy even though they pass courses and perform well during science courses.

3. Interest in studying science now and in the further declines in the K-12 years.

4. Traditional science instruction negatively affects students curiosity and ability to offer explanations, to devise tests, to predict causes and consequences.

5. There is no evidence that the recent science teaching produces people who possess the traits that characterize scientifically literate people.

Aikenhead (2003) is much of the opinion of Yager and pinpoints the major failures of science education as the following:

1. The first failure is concerned with the primary goal of school science: to produce knowledgeable people to go into careers in science and related jobs; or at least support those who do. The results from many researches show that students lose their interest to continue studying science during high school, and then during university undergraduate programs. Most researches on students' views of the science curriculum conclude that school science transmits content, which is socially sterile, impersonal, frustrating, intellectually boring, and/or dismissive of students' life-worlds.

2. The second major educational failure of the traditional science curriculum is that some strong science students lose their interest in taking further science classes, some students become interested in science for the wrong reasons, and many students become illiterate citizens with respect to the nature and social aspects of the scientific enterprise.

3. The third documented major failure dates back to the 1970s research on student learning: most students tend not to learn science content meaningfully. Furthermore, much of the research suggests that the goal of learning canonical science meaningfully is simply not achievable for the majority of students in the context of traditional school science.

According to Tytler (2007), there are four main elements could reflect the crisis in science education:

1. There is a clear evidence that students develop negative attitudes towards science over the secondary school years.

2. Students participation science subjects decreased over time.

3. A shortage of qualified and skilled people in the field of science.

4. A shortage of qualified and well-prepared science teachers.

In other words, the development of new science and technology and the ongoing progress of society made a lot of changes in science education. It has leaded to new concepts, new modes of thinking, new teaching materials, new teaching approaches, and new technical devices in the field of education. As a result, in a post-modernist curriculum the 
following characteristics are revealed which have a practical impact on curriculum development and implementation (Van Loggerenberg-Hattingh, 2000):

1. A reduced amount of science curriculum content. Science curriculum should focus on the mastering of general competencies and fundamental relationships in students' life.

2. A flexible and meaningful integration of any new knowledge and processes in the curriculum to make it relevant to students' life.

3. The emphasis in the science curriculum must be on holistic concepts rather than concepts memorization.

\section{Effects of context-based approaches}

As a reaction to what was viewed as an overemphasis on subject matter and cognitive learning, advocates for this view promoted the idea of humanising schools. This curriculum gained impetus with the growth of child psychology which deals with issues such as valuing, freedom to learn and personal fulfilment (Van Loggerenberg-Hattingh, 2000).

Aikenkead identified that "humanistic perspectives in the science curriculum have been described in various ways, including: values, the nature of science, the social aspects of science, and the human character of science revealed through its sociology, history, and philosophy" (Aikenhead, 2007).

Bennett, Hogarth, and Lubben (2003) summarized meta-analysis of 66 studies of the effects of context-based approache. They reviewed studies that used contexts as the starting point for the development of scientific ideas in the teaching of secondary school science. The meta-analysis showed the following interesting results:

- context-based approaches motivate pupils in their science lessons.

- context-based approaches foster more positive attitudes to study science.

- context-based approaches increase pupils' understanding of scientific ideas.

Similarly; Aikenhead (2005) obtained the same results about STS science education in terms of curriculum development, student learning, and teacher orientations toward such a curriculum. His results support the claims that teaching students in STS science classes (compared with traditional classes) can significantly improve their understanding of social issues, their attitudes towards science and science classes. They can make modest as well as significant gains in thinking skills as a result of learning STS content. Besides, some students can enhance their socially responsible actions and increase their abililty to make decision (Aikenhead, 2007).

In general, the main characteristics of context-based scnince curriculum are (Van Loggerenberg-Hattingh, 2000):

- Science will be portrayed as a dynamic field challenging established truths. Scientific activity is regarded as a human activity which is responsive to human and societal perceptions and needs. Science is no longer viewed as mechanistic, impersonal and ultimately objective.

- Because of the integrated and inter-related nature of reality, content will rather be organised around themes and problems, than around the structure of a single discipline.

- The curriculum will be sensitive to the values of multiple cultures, races, males and females and will allow for different teaming styles.

- The curriculum will devise co-operative and collaborative learning experiences which will discourage a teacher-centred and teacher-dependent attitude. It implies a break away from a textbook and lecturing approach to an activity-based. hands and minds on approach.

- The curriculum will focus on open-ended inquiry and communication, rather than drill and practice.

In conclusion, the reported results of using context-based approaches in science education are positive regarding developing students' attitudes towards science. However, they are somewhat disappointing from a cognitive development point of view. This lack of effectivness could be explained by a weak relationship between contexts and relevant concepts in the perception of students and teachers (Bennett et al., 2003).

\section{Objectives of the Study}

In view of the current call for making a link between the students' life and science curriculum and the reflection of this trend in science curriculum, this study aims :

1. to discuss the curriculum development process.

2. to propose a model curriculum for developing context-based physics curriculum. 


\section{Definition of Terms}

\subsection{Curriculum}

Different people identify a curriculum in different ways and sometimes in multiple ways depending upon the context in which the concept is used. The most common perceptions of curriculum expanded substantially from the types identified by John Goodlad (In: (Saylor, Alexander, \& Lewis, 1981)) and suggested by Glatthorn (In: (Print, 1993)) which may be described as:

- The ideal / recommended curriculum : Beliefs of scholars as a solution to meet the need and consequently perceived as the most appropriate curriculum for learners;

- The entitlement curriculum: What society believes learners should expect to be exposed to as part of their learning to become effective members of that society;

- The formal curriculum (Explicit/ intended/ written curriculum): What organizations develop for the learners in their educational systems and what should be done in the class as seen in syllabi, guidelines, textbooks, etc.;

- The instructional/ perceived curriculum :what teachers report they do or trying to do;

- The operational / observed curriculum :what actually goes on in the classroom;

- The experiential curriculum: what the students are perceiving and reacting to; and

- The attained curriculum: the measurement of student learning (usually through a testing process) which reveals those learnings acquired by students.

According to the traditional view, the curriculum definitions emphasize on the rule of the teacher and the ways of organizing the knowledge, while the contemporary view of the curriculum emphasis on the learning experiences and the students positive role in the learning process. Its clear that the learners' planned experiences in the school will survive under the teachers' guidance.

In this research, the curriculum definition is "the plans made for guiding learning in schools, usually described in documents (textbooks, curriculum guides, course syllabus, lesson plans) of several levels of generality, and the execution of those plans in and out the classroom. As experienced by learners; those experiences take place in a learning environment (classroom, laboratory, outdoors) which also influences what is learned" (Hassard, 2005). This definition means that 'curriculum' is not only what is written in the syllabus but also encompasses among others things. For example, curriculum maybe includes courses and subject designs and development, teaching and assessment strategies, facilities, timetabling and access to information. It is obvious that the curriculum is affected by what is and is not included.

\subsection{Curriculum Development}

According to the literature review of curriculum development, the term 'model' has been used to explain both the nature and process of curriculum development. Print (1993) points out that the frequently used models in developing curriculum are the graphical models that enable curriculum developers to visualize curriculum elements, their relationships, and the processes of development and implementation. Curriculum Development is a comprehensive, ongoing, cyclical process "to analysis the situation; to develop aims or objectives to address the results of the situation analysis; to determine an appropriate content, teaching methods, learning activities and teaching evaluation; and to carry out a formative evaluation of the context-based curriculum that results from these processes".

\subsection{Context-based science curriculum}

In context-based science curricula - such as ChemCom, PLON, Salter's Science, Chemie im Kontext and Physik im Kontext - practical applications and/or socioscientific issues act as a starter for the teaching-learning of science (Kortland, 2011). It is an "event centered learning" whereby real-life events provide the motive for curriculum planning (Pedretti, 1996). It was and still is expected that relating science to 'everyday life' would make science teaching more interesting for a high percent of the students, that they would be more motivated to learn about and thus would reach a better understanding of the subject knowledge involved. This implies that the science content presented is necessary, and thus its learning is meaningful, for solving a practical or theoretical problem set by the context.

The developed curriculum is context-based. In this approach, the contexts, real life events and applications of science and technology are used as the starting point for taeching and developing students' ideas about science and 
teachnology. This means that taking the students' 'life world' as a starting point, the process of curriculum development takes into account technology, natural phenomena, socio-scientific issues, the nature of science and the interrelations between science, technology and society in science curriculum.

\section{Research Methodology}

Documentary analysis was used to describe and analyze the existing curriculum. According to Mogalakwe (2006) the use of documentary methods refers to the analysis of documents that contain information about the phenomenon we wish to study, it is a technique used to categorize, investigate, interpret and identify the limitations of physical sources, most commonly written documents whether in the private or public domain. Two types of documents could be used in documentary study; primary documents and secondary documents. Mogalakwe (2006) mentioned that primary documents "refer to eye-witness accounts produced by people who experienced the particular event or the behavior we want to study". On the other hand secondary documents are "documents produced by people who were not present at the scene but who received eye-witness accounts to compile the documents, or have read eye-witness accounts. Documents range from public through private to personal documents" (Mogalakwe, 2006).

Similary, Chism (1999) declared that "documentary analysis is the systematic examination of instructional documents such as syllabus, textbooks and course evaluation results in order to identify the needs and the challenges". It can also help the researcher to collect information about an instructional approach and learning activity. Chism (1999) identifies several types of instructional documents that can be analyzed: course policy and practices, syllabus, ground rules for discussion, course guides, and course content.

The analysis of the curriculum documents helped the researcher to identify the characteristics of the existing curriculum, and to determine the extent to which there was a need to adjust the curriculum to suit context base approach. For instance, the statements of objectives of the science curriculum were to be reviewed to determine the extent to which they would be in agreement with the context base approach. This procedure enabled the researcher to identify the curriculum objectives that need a modification or adding up. To analysize the documents, the researcher used the following procedures:

1. Developing a review plan which included:

- Defining the objectives of the plan.

- Determining the required documents: to identify and review their relation to the science curriculum in terms of the curriculum framework, its objectives and content.

- Determining the whereabouts of these documents.

- Set a check list that reflects the objectives of the analysis, such as:

i. The objectives related to context based approach.

ii. The extent to which the science curriculum framework aligned with context based approach.

iii. The need to add new components to the existing curriculum according to context based approach.

iv. The components of the current curriculum, which must be reconsidered.

2. A time-plan for the document analysis process. After deciding the objective of the analysis and the reference index that the analysis should refer to, the researcher analyzed the following:

- Curriculum framework: This includes the general philosophical framework of Education in some Arab countries like Yemen, objectives of education, goals of the educational grades, and objectives of teaching science. Also, it includes organizing the contents of science curriculum in the secondary grade. The researcher made sure that these curricula documents included context based approach characteristics such as learner-orientation level, applicability of science etc.

- School textbooks: The researcher checked the following:

i. Number of subjects that are related to context based approach

ii. Methods of infusion of context issues (if available) in the book.

3. Based on the results of analyzing the science curriculum documents and its characteristics that were built to suit context based approach characteristics, the researcher set out to develop the new curriculum.

\section{Models of Curriculum Development}

A model is a simplified representation of reality that is often depicted in diagrammatic form. The purpose of a model is to provide a structure for examining the variables that constitute reality as well as their interrelationships. Scientists in 
curriculum development have accepted the use of the term 'model' to explain both the nature and process of curriculum development. The models may be considered in many different ways, depending upon the purpose for which they are intended. In general, curriculum development models are graphical models since they enable curriculum developers to visualize curriculum elements, their relationships, and the processes of development and implementation (Print, 1993).

A review of literature in the curriculum area reveals that many ideas have been suggested for models or steps to be taken in curriculum development process. The salient curriculum development process model were approcieted are classified into three categories; rational, cyclical and dynamic. A representative sample of the different aspects has been included in the form of a continuum of curriculum models (figure 1).

The continuum (as seen in Figure 1) describes two extremes of the curriculum process. The rational or objectives models are sequential, rather rigid approaches to viewing the curriculum process, while at the other extreme may be found dynamic or interaction models, which view curriculum processes as flexible, interactive and modifiable. In between, models gradually change from one type to the other.

1. Tyler's Model (As an example of objectives models)

In his book "Basic Principles of Curriculum and Instruction" in 1949, Tyler argues that curriculum development needs to be treated logically and systematically (Print, 1993). Briefly, his model for the curriculum process is outlined in figure 2.

It is clear from the diagram that the model is linear in nature; it consists of four steps, the four steps are "objectives", "content", "method" and "evaluation". The first step of this model is to think about educational aims and objectives, and secondly about the kinds of subject matter or experiences that require effective organization to help students achieve those objectives. These two views then need to be put together programmatically. The results of using the curriculum need to be evaluated in some way, so the final step in Tyler's process was to determine whether the objectives had been achieved or not.

Certainly, Tyler has had a significant effect upon curriculum developers and writers for the past three decades of the twentieths century.

2. Hilda Taba (As an example of objectives models)

Of the several books that Hilda Taba wrote on curriculum, the most well known and influential was "Curriculum Development: Theory and Practice" published in 1962. In this work, Taba outlined her ideas of the process of curriculum development. Taba's model is linear in approach; it's similar to Tyler's basic model. In fact, she modified Tyler's model to become more representative of curriculum development. So that she argued for more information input at each stage of the curriculum process. Taba argues that if curriculum development was to be logical, orderly; the way of developing the curriculum would follow seven sequential steps as outlined in figure 3 (Sada'a \& Ibrahim, 2004).

According to Print (1993), Taba contends that "scientific curriculum development needs to draw upon analyses of society and culture, studies of the learner and the learning process, and analysis of the nature of knowledge in order to determine the purposes of the school and the nature of its curriculum" (Print, 1993).

3. Wheeler's Model (As an example of cyclical models)

Wheeler's developed a model for curriculum design, it is an improvement upon objectives models (espically, Tyler's model). Wheeler model for curriculum design is a cyclical model (figure 4); developers can start from any point of the circle. For example, the evaluation stage is not terminal; the outcome from the evaluation could be a good feedback to set the curriculum objectives and goals, which, of course, will influence other stages of the curriculum development and design. In his model, Wheeler contends that: (Print, 1993; Sada'a \& Ibrahim, 2004)

- Aims are formulated from the general to the specific in curriculum planning.

- Content is distinguished from the learning experiences which determine that content.

4. Print's Comprehensive Model (As an example of Dynamic/interation models)

After analyzing many curriculum development models, Print (1993) Print (1993) adopted a comprehensive model of curriculum development. Print views his model as logical and sequential in approach, cyclical in its development of a curriculum product and yet concerned with applying the model to realistic situations. It is a model that has the flexibility to be used for developing many types of curriculum.

Three phases organization, development and application are considered to form the basis of this model of curriculum development. Figure 5 depicts the three phases. Print (1993) illustrates these three phases as follow:

Phase 1: Organization: According to Print (1993), the curriculum presage concerns of the foundations or forces that influence developers' ways of thinking about curriculum. He said thatPrint (1993): 
1. Curriculum foundations are "the components that influence and control the content and organization of the curriculum".

2. They depends on the values one has developed about knowledge, society, learning, and the individual.

3. Curriculum foundations derived from philosophical, sociological and psychological sources".

Phase 2: Development: To achieve the second phase; developers follow the cyclical procedure in the model as seen in figure 5. In other words, they follow the sequence of curriculum elements that begin with situational analysis and continue with aims, goals and objectives; content; learning activities; evaluation and then continuing on to situational analysis again.

Phase 3: Application: The third phase of the model "application" which in turn incorporates three sets of activities:

4. Implementation of the curriculum: For any curriculum document, materials or project to be implemented in a school or school system, change must occur. To make this change occur effectively and with minimal disruption and confusion, a plan for implementing the curriculum innovation must be devised.

5. Monitoring of and feedback from the curriculum: It is an important step in gauging the success of the curriculum activity.

6. The provision of feedback data to the presage group: it relates to life forwarding of feedback data to the curriculum presage group.

\section{Appropriate Curriculum Model}

The previous description of the models of curriculum development shows that there are many types of models. According to their characteristics, they could be classified into three types: the rational or objectives /classical models, the cyclical models, and the dynamic or interaction models. In between, models gradually change from one type to the other.

Rational models sometimes referred to as objectives/classical/means-end models, these approaches to the curriculum development beginning with curriculum objectives and following a sequent from objectives to content, teaching methods and finally evaluation stage. Two principal proponents of rational models are Ralph Tyler and Hilda Taba. The main advantage of these models is providing simple, time-efficient approaches to meet the curriculum development, while a significant weakness of the objectives model arises from the unpredictable nature of teaching and learning. The model prescribes specified objectives to be achieved, but often learning occurs beyond these objectives due to factors that could not have been foreseen.

On the contrary, Cyclical models view elements of the curriculum as interrelated and interdependent, so that the distinctions between the elements are less clear than in the rational model. Strengths of cyclical models derived from a logical sequential structure upon which curricula may be devised, otherwise, employing situational analysis as a starting point, provide feedback upon which objectives are effective or not, and these models are flexible and less rigid in their application than the others. Inherent weaknesses within cyclical models are more difficult to locate largely, and the fundamental problem in utilizing such models is the amount of time required to undertake an effective situational analysis.

Comparing with rational models, the interactive or dynamic models of curriculum offer an alternative view of the process of curriculum development. Proponents of these models argue that the rational and cyclical models do not reflect the reality of curriculum development process. They contend that it does not follow a lineal, sequential pattern and can commence with any curriculum element and proceed in any order. The dynamic models have emerged from the analyzing of what really happened through the process of curriculum development.

Unlike the objective model, dynamic models do not consider objectives important; therefore, it is not difficult to suggest that dynamic models appear confusing and lacking in direction. According to Print (1993) it's impossible to suggest that only one model of curriculum development is appropriate in all contexts and to all curriculum developers. This is why Curriculum developers should select the most appropriate model for their context.

Oliva (2005) confirmed that before choosing a curriculum development model, it is important to outline the criteria or characteristics that should be in. Oliva pointed out that the model should show the following: (Oliva, 2005)

1. Major components of the process, including stages of planning, implementation, and evaluation

2. Customary, but not inflexible "beginning" and "ending" points

3. The relationship between curriculum and instruction

4. Distinction between curriculum and instructional goals and objectives

5. Reciprocal relationships among components 
6. A cyclical pattern

7. Feedback lines

8. The possibility of entry at any point in the cycle

9. An internal consistency and logic

10. Enough simplicity to be intelligible and feasible

11. Components in the form of a diagram or chart

Curriculum development refers to all aspects of the curriculum development process. It includes reviewing the current situation, development of aims and objectives, make decisions on content and structure, suggestions for learning activities and teaching methods, developing assessment strategies, as well as evaluating the curriculum development procedures.

\section{The process of Developing Context based curriculum}

According to Kortland, "Any science curriculum could be characterised by a 'correct explanations' and a 'solid foundation' emphasis. Context based curriculum give more emphases of 'everyday coping', 'making decisions about science, technology', 'development of scientific skill ', 'structure of science' and 'self as explainer"' (Kortland, 2005).

Similarly, Print (1993) pointed out five major stages for the process of curriculum development. Those are:

1. Situational analysis

2. Formulation of objectives.

3. Selection and organization of content.

4. Selection and organization of learning activities and teaching methods.

5. Evaluation.

These five stages constitute the curriculum development process.

\subsection{Situational Analysis}

The Curriculum Framework outlines the principles guiding curriculum development, the organization of the general and further education bands, as well as the learning areas to be addressed. In addition to a Curriculum Framework it will be necessary to draw up a separate detailed framework outlining the new modular structure and rules of combination for qualifications in the Further Education. Therefore, curriculum development should begin with a Curriculum Framework as a realistic appraisal and analysis of the existing situation. An 'analysis of the situation' provides an opportunity to get feedback regarding the strengths, weaknesses and possible future development of the curriculum. By that, developers can then devise appropriate content. Similarly appropriate learning activities can be organized so that the content is learnt effectively and thus the objectives achieved.

\subsection{Aims, Goals And Objectives}

The process of aims and goals' determination is the first and most important step in the curriculum planning and design process. Aims and goals are the essential element that guide the process of choosing the unique content, methods and teaching strategies, learning activities, and the assessment and evaluation processes for the learning outcomes that the curriculum developer intents to achieve.

Regarding how should science teachers teach within the students' life context, NSTA recommends that:

"science instruction incorporate scientific issues that are personally and socially relevant, and developmentally appropriate, as a way to generate interest in and motivation to engage in relating science to personal and societal issues; focus as much as possible on scientific and technological issues that are identified by students; incorporate the practices and understanding of scientific inquiry and technological design; provide multiple learning opportunities that encourage the study of science in personal and societal contexts; provide an authentic learning context by examining the societal dimensions of scientific issue, such as political, economic, and ethical considerations; approach decisions in an open unbiased way, respecting and acknowledging different perspectives, views, beliefs, and other ways of knowing; prepare students to become future citizens who are scientifically and technologically literate and willing to engage in making responsible and informed decisions (National Science Teachers Association, 2000).

Affective outcomes along with cognitive outcomes are promoted by the humanistic curriculum (Van LoggerenbergHattingh, 2000). The aims of education put forward by the context based science curriculum into a balance between 
preparing students for further education and/or future employment and for coping with their (future) life roles as a consumer and citizen in a technologically developing, democratic society (Kortland, 2005). Considering the nature of Arabic countries and the Islamic perspective, the researcher suggests the following aims for the developed context-based science curriculum.

\section{A. Attitude and Values:}

1. Encourage the learners to develop deep belief in Allah and their Islamic beliefs, and develop positive attitudes towards Islam and the Islamic values.

2. Appreciate the contributions of Arab and Moslem scholars to scientific and technological development.

3. Increase the learner's awareness of the efforts of a society to encourage and develop science and taking the benefits from its outcome for comprehensive development.

4. Enable students to appreciate the contributions of science and technology towards national development and the well-being of humanity.

5. Enable students to consider further studies and careers in science and technology-related fields.

6. Encourage the students to develop attitudes that support collaborative activity.

7. Encourage the students to increase their concern for safety.

B. Knowledge:

1. Provide the learner with a coherent and functional scientific knowledge, facts, concepts, generalizations, principles, and theories in the different fields of science.

2. Provide the learners with a historical perspective about biology, ecology, chemistry, and physical science in the 19th century.

3. Increase the learner's awareness that theories and scientific methods are changeable and developed as a results of individuals and communities, and realize that its applications are useful for individuals, environment and communities.

4. Provide the learners with culture and scientific preparing for increase their interest in further studying of science, and pursue career possibilities within science-related fields.

5. Increase the learner's awareness of the importance of dealing effectively towards the different applications of science, and take care of his health and environment and play an active role in its preservation and conservation.

6. Acquire knowledge to analyze and explain the interrelationship between science, technology, society and environment; and how the individuals influence them.

7. Acquire knowledge to explore the nature of science and its domains, and outline the importance of science and its relationship with other disciplines and technology.

8. Enable learner to acquire new scientific and technological knowledge and use it to evaluate and make decisions about real-world issues related to the applications of science and technology, considering a variety of perspectives.

C. Skills:

1. Enable the learner to acquire the scientific, critical, and creative thinking skills, which improve his skills of problem solving.

2. Encourage the learner to ask questions and plan investigations about his observations by using safe and skillful tools and techniques to collect data and gather information.

3. Work as a member of a team in solving problems related to socio-scientific issues.

The previous curriculum outcomes identify what students are expected to know and value by the end of grades 12 because of their cumulative learning experiences in science.

\subsection{The Content}

According to Aikenhead (1994) there are three essential groups of possible curricula (each linking everyday contexts and school science). Figure 6 illustrates these three groups. A context-based means that the science courses taught through issues from society (and/or technology); while context-infused, related to science courses that incorporate issues from society (and/or technology); and the context-focused products courses about issues in society (and/or technology) including the required science.

The selected social and scientific contexts would be influenced by the differences in students' interest, their abilities and plans for the future, and by long-term developments in society (Kortland, 2005). A lot of attention should be 
given to the introduction and use of contexts to bridge the gap between meanings of concepts in a science context and in students' daily life. The following are the characteristics of adequate contexts (De Jong, 2006):

- Contexts should be well-known and relevant for students

- Contexts should not distract students' attention from related concepts

- Contexts should not be too complicated for students

- Contexts should not confuse students

It is crucial to select adequate contexts for incorporating in science curriculum, especially when teachers starts their teaching using these contexts. De Jong (2006) pointed out many reasons to give a lot of attention for the selected contexts: (De Jong, 2006)

1. The irrelevant contexts will not motivate students to study.

2. The interesting contexts could distract students' attention from the related concepts.

3. The contexts could be too complicated, so students will not be able to make proper links with science concepts.

4. The contexts can be confusing for students.

In conclusion, a careful selection of contexts for incorporating in science curriculum is an important process for improving context-based science curriculum.

\subsubsection{Teaching methods}

The context-based curriculum differs from the traditional curricula. Context-based required more discussions and openended questions by a student and classmates. From the constructivism points of view, students actively construct meaning for themselves because of direct, hands-on science experiences, minds-on simulations, and social interactions with other students and/or the teacher will be the considered in the learning activities. The instruction within contextbased includes simulation games and role-playing, forums and debates, individual and cooperative learning, active research fieldwork, guest speakers, and community action. The teacher roles to introduce a context to students at the start of a unit; content is then taught on a need -to know-basis, and concepts are discussed as they arise (King, 2008).

According to many psychologists, activities and teaching methods which are associated with this curriculum approach, include the following (Van Loggerenberg-Hattingh, 2000):

- Lessons based on real life experiences.

- Field trips and group projects.

- Homework and tutoring centers.

- Co-operative, independent and small group learning as opposed to large group, competitive teacherdominated learning

\subsubsection{Teacher-student interaction}

In relation with the changes in teaching methodology, the 'distance' between teacher and students became smaller. Overall, the activities will shift the teacher's role to a classroom manager (managing time, people resources and the emotional classroom environment), away from the role of a classroom performer (Hofstein, Aikenhead, \& Riquarts, 1988).

Through small group and whole class discussions, the students are expected to critically analyze a variety of issues, make decisions, provide justifications for their decisions. The main characteristics of this instruction include (Tal \& Kedmi, 2006):

- Active learning through searching for information, collecting data and doing hands on lab-activities.

- Social interaction by participating in small group work and whole class discussions.

- The use of authentic learning materials derived from professional magazines, daily newspapers and the Internet.

- Problem-based learning through analyzing real cases.

- Incorporating the outdoors through field trips.

\subsubsection{The Sequencing of Instructional Topics}

Aikenhead (1992) has developed a model of the interface between science, technology, and society (Figure 7), this model may help in the sequencing of instructional topics for context-based curriculum. Aikenhead attaches a ring of 
"technology" around a circle of "science content," and places this on a backdrop of "society." Imagining a vector passing through the diagram, we can follow his idea of sequence. Making decision and taking action is the main goal of teaching any context-based content. Aikenhead (1992) described the sequencing of instructional topics will be as the following:

1. The instruction could start with a discussion of the societal aspects of an issue.

2. The instruction could cover technological aspects of the issue, in order to understand a societal problem; there is usually some technology to examine. The domain of technology is represented by the gray donut in Figure 7.

3. The instruction could present science concept information related to an issue; this science content will help students understand the technology and the societal issue.

4. Finally, the arrow in figure 7 ends in the domain of society. Here students often address the original key question or issue and then make a decision and take actions.

This sequencing could bring many benefits, once the science concepts are understood; the students reconsider the technological and societal issues, and attempt to make informed decisions or predictions about the issue.

\subsection{Evaluation}

Evaluation is broader in scope than measurement in that it involves the interpretation of measurement data. In planning evaluation, we can use a wide range of approaches to give students opportunities to show their cognitive, affective and psychomotor abilities. Teachers could use different types of assessment and evaluation strategies to gain information about students' performance, including, but not limited to, the following:

- Teacher-made and other tests

- Performance assessment tests

- Portfolios

- Brochures and Learning journals

- Peer assessment

- $\quad$ students' self-assessment

- Debates and Conferences

- Formal and informal observations

Results of assessments and evaluations have a broad range of uses, such as (Graham, Bernard, Johnston, \& Larsen, 2014):

- providing feedback to improve student learning and encourages them for better achievement

- determining if curriculum outcomes have been achieved

- certifying that students have achieved certain levels of performance

- setting a new goals for student's future learning

- providing feedback to parents about their children's learning

- providing feedback to teachers on the effectiveness of their teaching and the learning environment

Assessment and evaluation are an essential process of learning and teaching. The context-based science curriculum encourages students to learn scientific processes and knowledge within meaningful contexts. As a result, assessment strategies should reflect and be consistent with context-based emphasis.

\section{Conclusion}

The aims of a context-based curriculum are to achieve a balance between preparing students for their future life, further education and future employment and career. Therefore, a context-based curriculum put into account students' 'lifeworld' as a starting point of the science instruction. It also gives more emphasis on technology, environment, socio-scientific issues and the nature of science.

\section{References}

Aikenhead, G. S. (1992). The integration of STS into science education. Theory into Practice, 31, 27-35.

Aikenhead, G. S. (1994). What is STS teaching? . In J. Solomon \& G. S. Aikenhead (Eds.), STS education: International perspectives on reform (pp. 47-59). New York: Teachers College Press.

Aikenhead, Glen S. (2003). Review of research on humanistic perspectives in science curricula. Paper presented at the the European 
Science Education Research Association (ESERA) Conference, Noordwijkerhout, The Netherlands http://www.usask.ca/education/people/ aikenhead/ESERA_2.pdf.

Aikenhead, Glen S. (2005). Research into STS Science Education. Educación Química, 16, 384-397.

Aikenhead, G. . (2007). Humanistic Perspectives In The Science Curriculum. In Handbook of research on Science Education (pp. 881910).

Bennett, J., Hogarth, S., \& Lubben, F. (2003). A systematic review of the effects of context-based and STS approaches in the teaching of secondary science. Research Evidence in Education Library. London: EPPI-Centre.

Blosser, P. E. , \& Helgeson, S. L. (1990). Selected Procedures for Improving the Science Curriculum. ERIC Clearinghouse for Social Studies/Social Science Education $\mathrm{OH}$.

Brunhorst, B. , \& Padilla, M. . (1986). Science education for middle and junior high students. Science and Children, 24(3), 62-63.

Chism, N. V. N. (1999). Peer Review of Teaching: A Sourcebook. Bolton, Mass.: Anker Publishing.

De Jong, O. (2006). Making chemistry meaningful: conditions for successful context-based teaching. Educación Química, 17, $215-226$.

Donnelly, J. F. (2004). Humanizing Science Education. Science Education, 88(5), 762-784.

Eijkelhof, H. , \& Lijnse, P. (1988). The role of research and development to improve STS education: experiences from the PLON project. International journal of Science education, 10(4), 464-474.

Hassard, J.(2005). The Art of Teaching Science. New York: Oxford University Press.

Hofstein, A., Aikenhead, G.S., \& Riquarts, K. (1988). Discussion over STS at fourth IOSTE symposium. International Journal of Science Education, 10, 357-366.

Graham, E., Bernard, J. B., Johnston, T., \& Larsen, B. (2014). Prince Edward Island Grade 6 Mathematics Curriculum Guide. Canada.

King, D. (2008). Teacher beliefs and constraints in implementing a context-based approach in chemistry. An Electronic Journal for Leaders in Education, 6(6).

Kortland, J. (2005). Physics in personal, social and scientific contexts: A retrospective view on the Dutch Physics Curriculum Development Project PLON. In P. Nentwig \& D. Waddington (Eds.), Making it relevant. Context based learning of science (pp. 67-89): Munster: Waxmann.

Kortland, J. (2011). Scientific literacy and context-based science curricula: Exploring the didactical friction between context and science knowledge. In D. Hoettecke (Ed.), Naturwissenschaftliche Bildung als Beitrag zur Gestaltung partizipativer Demokratie (pp. 1731). Berlin: LIT Verlag.

Oliva, P. F. (2005). Developing the curriculum (6th ed.). Boston: MA: Pearson Education, Inc.

Mogalakwe, M. (2006). The Use of Documentary Research Methods. African Sociological Review, (1), 221-230. doi:10.1353/eas.0.0006

National Science Teachers Association, N. (2000). Position Statement_Teaching Science And Technology (p. 1.-3).

Pedretti, E. (1996). Learning about science, technology, and society STS through an action research project: Co-constructing an issuesbased model for STS education. School Science and Mathematics, 96, 432-440.

Print, M. . (1993). Curriculum Development and Design (2 ed.). Sydney: ALLEN \& UNWIN.

Sada'a, G. , \& Ibrahim, A. (2004). Curriculum Organizations; Its Planning And Development. Cairo, Egypt.: Dar Al-Thakafah.

Saylor, J. Galen, Alexander, William M., \& Lewis, Arthur J. (1981). Curriculum Planning for better Teaching and Learning. Newyork: Holt, Reinhart and Winston.

Tal, T., \& Kedmi, Y. (2006). Teaching socioscientific issues: Classroom culture and students' performances. Cultural Studies of Science Education, 1, 615-644. doi:10.1007/s11422-006-9026-9

Tytler, R. . (2007). Australian Education Review. Re-imagining Science Education, Engaging students in science for Australia's future. Australia: Australian Council for Educational Research.

Wraga, W. G. , \& Hlebowitsh, P. S. (1991). STS education and the curriculum field. School Science and Mathematics, 91(2), 54-59.

Van Loggerenberg-Hattingh, A. (2000). Implementing a problem-based learning model in the training of educators for an outcomesbased technology curriculum. Pretoria: university of Pretoria

Yager, Robert E. (1991). The constructivist learning model: Towards real reform in science education. Science Teacher, 58(6), 52-57.

Yager, Robert E. (1993). Science-Technology-Society As Reform. School Science and Mathematics, 93(3), 145-151.

Yager, Robert E. (2002). Achieving the Visions of the National Science Education Standards. Paper presented at the The lowa Academy of Education. Occasional Research, lowa.

Zeidler, D. L., Sadler, T. D., Simmons, M. L., \& Howes, E. V. (2005). Beyond STS: A research-based framework for socioscientific issues education. Science Education, 89, 357-377. doi:10.1002/sce.20048

\section{Figures}

Figure 1: Continuum of curriculum models

\begin{tabular}{c|c|c}
\hline Rational/objectives models & Cyclical models & Dynamic/interation models \\
\hline Tyler & Wheeler & Walker \\
Taba & Audrey and Nicholls & Skilbeck \\
& & Kerr \\
& & Beauchamp \\
& & Print
\end{tabular}


Figure 2: Tyler model of the curriculum process (Print, 1993)

\begin{tabular}{cc} 
Objectives & What educational purposes should the school seek to attain? \\
\hline$\downarrow$ Selecting & What educational experiences can be provided that are likely \\
learning experiences & to attain these purposes? \\
\hline $\begin{array}{c}1 \text { Organizing } \\
\text { learning experiences }\end{array}$ & organized? \\
\hline 1 Evaluation & How can we determine whether these purposes are being attained?
\end{tabular}

Figure 3: Taba model of the curriculum process (Sada'a \& Ibrahim, 2004)

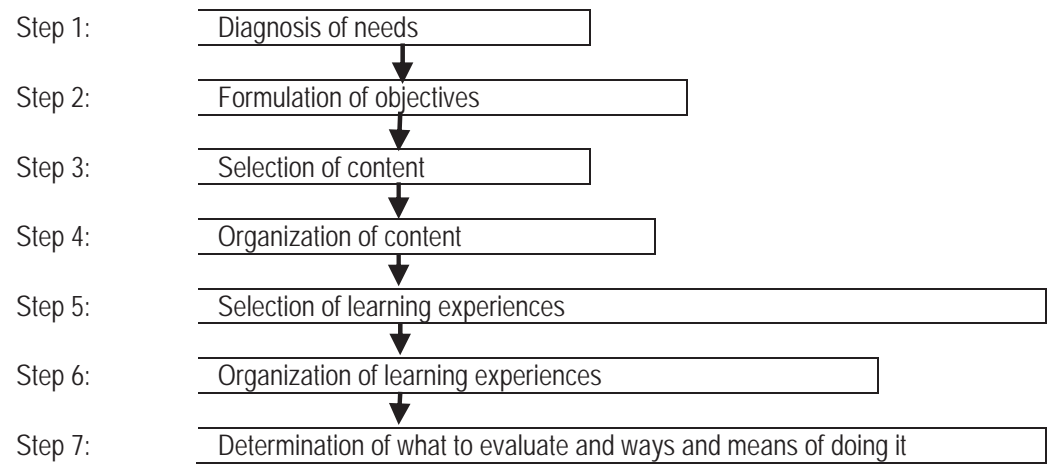

Figure 4: Wheeler's model

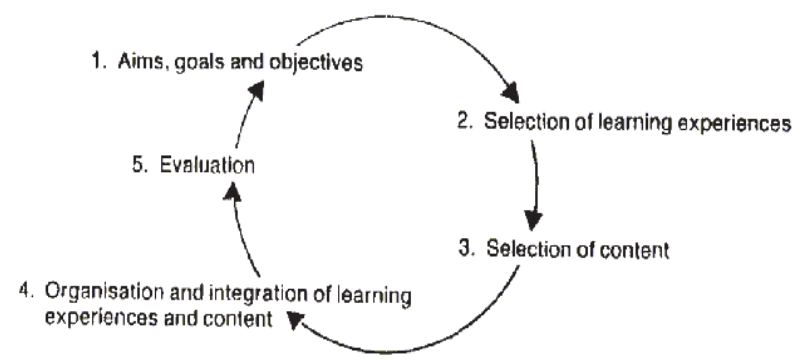

Figure 5: Print's Comprehensive Model

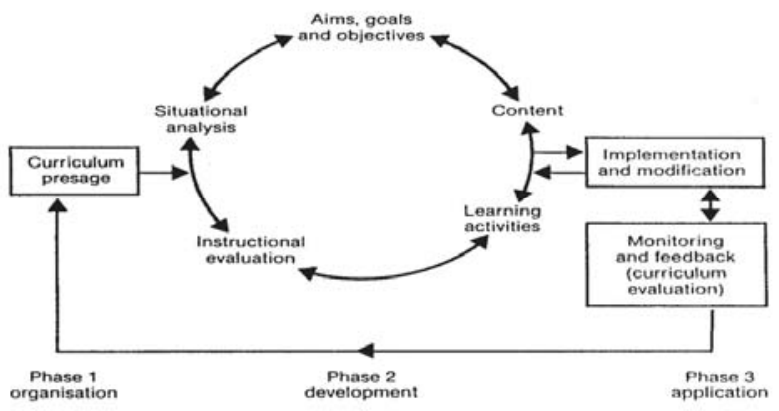


Figure 6: Ways of linking everyday contexts and school science

$$
\begin{aligned}
& \text { Context-infused } \\
& \text { Everyday context }
\end{aligned}
$$

Context-based

Everyday context
$\Rightarrow$
Context-focused

SCHOOL SCIENCE $\quad \Rightarrow$ everyday context

Figure 7: A schematic illustrating a possible sequencing of instructional topics

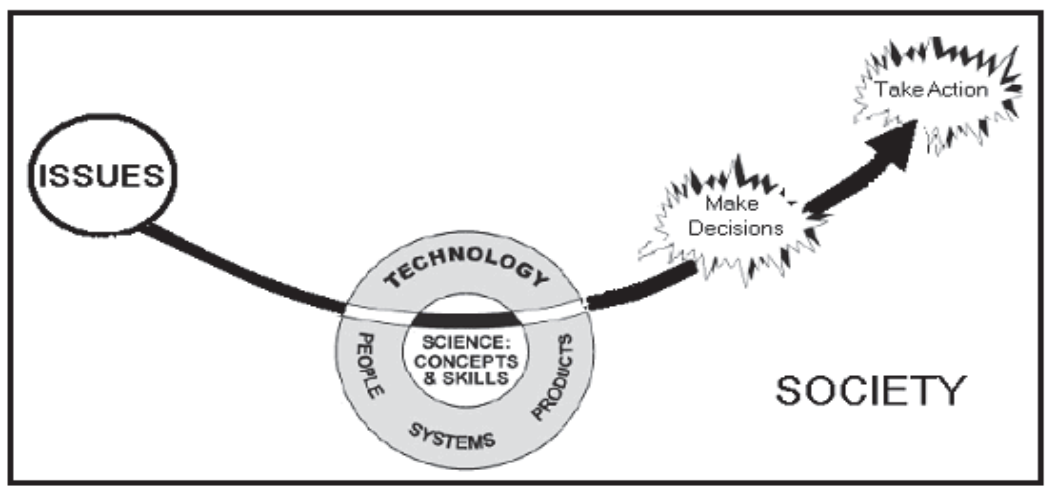

